\title{
A 18p11.23-p11.31 microduplication in a boy with psychomotor delay, cerebellar vermis hypoplasia, chorioretinal coloboma, deafness and GH deficiency
}

\author{
Mara Giordano1, Valentina Muratore ${ }^{2}$, Deepak Babu', Cristina Meazza ${ }^{2}$ and Mauro Bozzola ${ }^{2^{*}}$ (D)
}

\begin{abstract}
Background: Rearrangements involving the short arm of chromosome 18 have been extensively described. Here we report a microduplication of 320.5-431.5 Kb at 18p11.31-p11.23 in a 10 year-old boy.

Case presentation: In a 10 year-old boy with moderate psychomotor delay, hypoplasia of the cerebellar vermis, chorioretinal coloboma, deafness and growth hormone deficiency (GHD), an interstitial microduplication at 18p11.31-p11.23 was identified by array-CGH. This maternally inherited microduplication, encompasses three genes, namely ARHGAP28, LINC00668 and LAMA1 (a gene involved in cerebellum and retinal development).

Conclusions: The genotype-phenotype is discussed with particular attention to the LAMA1 gene, although it is difficult, as in many other similar situations, to assess the causality of the detected duplication in the absence of further studies aiming to explore the presence of co-occurring variants that could explain the incomplete penetrance.
\end{abstract}

Keywords: 18p11.31-p11.23 microduplication, Growth hormone deficiency, Hypoplasia of the cerebellar vermis, Chorioretinal coloboma, Deafness

\section{Background}

Rearrangements involving the short arm of chromosome 18 have been extensively described in the literature [1]. In most cases, patients carrying deletions of the whole arm (18p-syndrome), with breakpoints close to the centromeric region have been reported. The primary features of this condition include a cognitive impairment of varying severity, speech delay, short stature, holoprosencephaly, ptosis, pectus excavatum and dysmorphic features $[2,3]$. Pituitary hormone deficiencies have also been reported $[4,5]$. Conversely, $18 \mathrm{p}$ duplications are rare events in cytogenetic findings and only few cases are represented by pure duplications [1], being associated in most of the patients with 18q s or resulting from

\footnotetext{
* Correspondence: mauro.bozzola@unipv.it

${ }^{2}$ Internal Medicine and Therapeutics Department, Pediatric and Adolescent Unit, University of Pavia, Fondazione IRCCS Policlinico San Matteo, Pavia, Italy

Full list of author information is available at the end of the article
}

the unbalanced segregation of parental reciprocal translocations. For these patients, the phenotypic features could be the result of the excess of chromosome 18p material along with the imbalance of other chromosome regions.

Interestingly, there have been no reports of large interstitial duplication of 18p; nevertheless, with the introduction of microarrays some microduplications, with a likely pathogenic effect, have been identified. An 18p11.31-p11.32 duplication of $429.5 \mathrm{~Kb}$, including four genes, among which the likely causative EMILIN2, has been identified in a family with porokeratosis of Mibelli [6]. In the same region, other authors [7] detected a larger overlapping $2.6 \mathrm{Mb}$ microduplication involving at least nine genes in two siblings with variable levels of intellectual disability/developmental delay and behavioral difficulties. Finally, Kashevarova et. al [8] reported a 
microduplication of $351 \mathrm{~kb}$ at $18 \mathrm{p} 11.32$ in a boy with autism and dysmorphisms.

Here we report a microduplication of $320.5-431.5 \mathrm{~Kb}$ at 18p11.31-p11.23 identified through array comparative genomic hybridization $(\mathrm{aCGH})$, not overlapping with the previously described one, encompassing three genes, namely ARHGAP28, LINC00668 and LAMA1 in a 10 year-old boy with moderate psychomotor delay, hypoplasia of the cerebellar vermis, chorioretinal coloboma, deafness and growth hormone deficiency (GHD). The functional role of laminin alpha 1 in cerebellum and retinal development suggests that the duplication of LAMA1 may be responsible for at least some of the patient's clinical features.

\section{Case presentation}

A 7.5 year-old boy, the second child of nonconsanguineous Caucasian healthy parents (father 33 years-old, with a height of $161.5 \mathrm{~cm}$ and mother 36 years-old, $166.1 \mathrm{~cm}$ ) was referred to our Department because of short stature. His height was $110 \mathrm{~cm}(-2.25$ standard deviation score (SDS), weight $17 \mathrm{Kg}$ (body mass index (BMI) -4.78 SDS) and bone age 6.5 years. An intrauterine growth restriction was documented by ultrasound scan between the 20th and 22nd week of gestation. Labor was induced due to interruption of fetal development and fetal distress at 33 weeks. The birth weight was $1,450 \mathrm{~g}(-1.81 \mathrm{SDS})$, birth length $41 \mathrm{~cm}$ $(-1.49$ SDS $)$ and head circumference $28 \mathrm{~cm}(-2.29$ SDS). Apgar scores were 6 and 9 at 1 and $5 \mathrm{~min}$. He required intubation and mechanical ventilation because of pneumothorax. He was discharged from the Neonatal Intensive Care Unit after 37 days with the diagnosis of chorioretinal coloboma. The patient's family history was not significant for chromosome abnormalities, developmental delay or intellectual disability. His 3 year-old sister was healthy.

At 1 year of age, brain magnetic resonance image (MRI) showed lateral and third ventricle enlargement, stenosis of the aqueduct of Silvio and decrease dimensions of cerebellar vermis. These pathologic features were later confirmed by further MRI.

The patient had a history of significant developmental delay and intellectual disability. He sat at 13 months and walked at 2 years. He achieved language acquisition at 4 years and required speech therapist and psychologist care. At the age of 6 year the patient was diagnosed with bilateral mixed hypoacusis. At the age of 9.5 years, his intelligence quotient (IQ) was 49.

He presented dysmorphic features including microcephaly, triangular face, high forehead, protruding low set ears, small teeth, micrognathia, esotropia, epicanthus, right palpebral ptosis and flat feet (Fig. 1a).

At the age of 7.5 years, he was investigated because of short stature. After exclusion of celiac disease, malabsorption, inflammatory bowel disease, hypothyroidism and other chronic diseases, GH response to two pharmacological stimuli (arginine and glucagon) revealed a GHD (GH peaks: 4.8 and $8.1 \mathrm{ng} / \mathrm{ml}$, respectively; normal values $>10 \mathrm{ng} / \mathrm{ml}$ ). No other pituitary hormone deficiencies were found to be associated. MRI of the hypothalamic-pituitary region revealed a flattened pituitary gland (Fig. 2a, b). Substitutive GH therapy (0.21 $\mathrm{mg} / \mathrm{Kg}$ subdivided into 6 weekly subcutaneous injections) was started and led to a satisfactory increase in height (Fig. 1b).

\section{a}

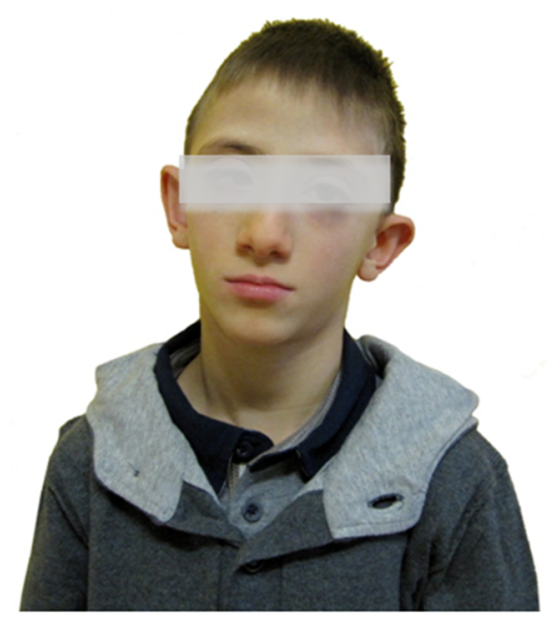

b

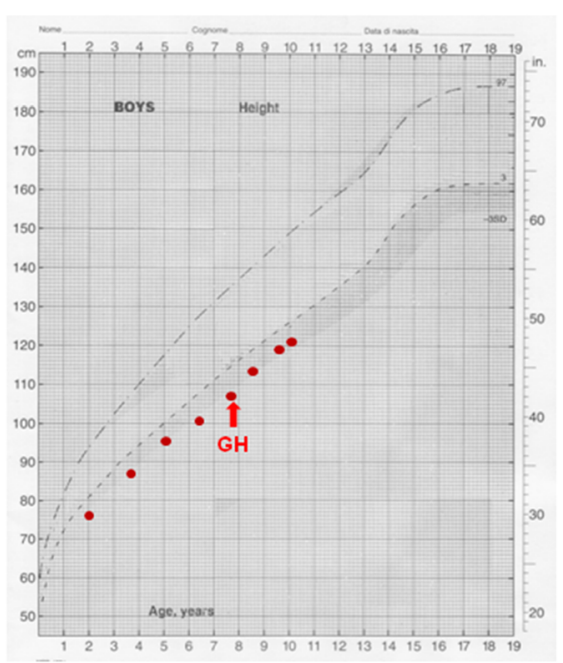

Fig. 1 a Dismorphic features of the patient at 7.5 years of age. Microcephaly, triangular face, high forehead, protruding low set ears, micrognathia, esotropia, epicanthus, right palpebral ptosis are shown. b Height curve of the subject. The arrow indicates the start of GH substitutive therapy 
a

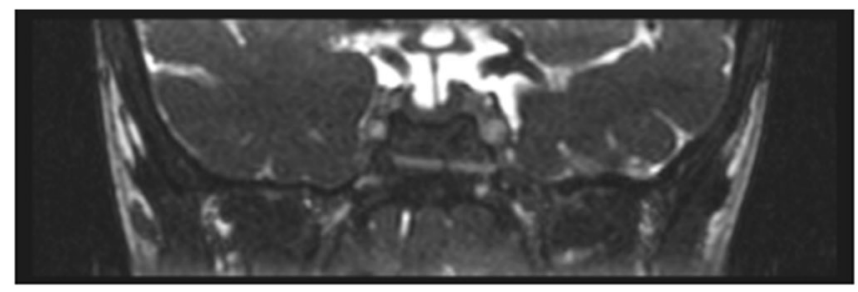

b

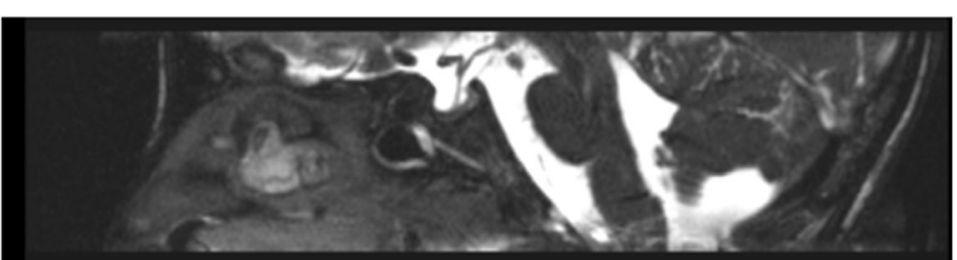

Fig. 2 Magnetic resonance imaging of the hypothalamic-pituitary region. Flattened pituitary gland. a coronal view. b sagittal view

\section{Methods}

Array Comparative Genomic Hybridization (aCGH) analysis

DNA was extracted from whole blood of the patient by salting out method and the Concentration and purity was measured with the NanoDrop spectrophotometer (NanoDrop Technologies, Inc.). Array CGH was performed using the standard Agilent Human Genome G3 SurePrint $4 \times 180 \mathrm{~K}$ Microarray (Agilent Technologies, California, USA), with median spacing of $13 \mathrm{~Kb}$. Labeling and hybridization were carried out according to the manufacturer's instruction (Agilent Technologies, California, USA).

The image of the array was acquired using the Agilent laser scanner G2565CA (Agilent Technologies, California, USA) and analyzed with the Agilent Feature Extraction software (v10.10.1.1.). Results were analyzed by Agilent Cytogenomics software (v2.5.8.11).

The presence of the duplication was confirmed in the patient and searched in his relatives through MLPA (Multiplex Ligation Probe Amplification) with a probe specifically designed within LAMA1 (chr18:70140937014542; GRCh37/hg19) using the SALSA MLPA probemix P200-A1 Human DNA Reference-1 (MRC-Holland).

Copy number variations (CNVs) reported in the Database of Genomic Variants [9] were excluded from further analysis.

We performed a search in DECIPHER database [10] and ClinGen [11] to search for patients carrying similar micro-duplications.

\section{Sequencing}

The $C D H 7$ and LIG4 genes were screened for the presence of causative mutations by direct sequencing. Briefly, genomic DNA was amplified by polymerase chain reaction (PCR) using primers designed to specifically amplify the coding regions and the intron/exon boundaries of each gene (see Additional file 1) The PCR products were visualized on a $2 \%$ agarose gel and purified using ExoSAP-IT enzymatic PCR clean up system (Affimetrix, Santa Clara, CA). The purified products were, then, sequenced with the Big Dye Terminator kit (Applied Biosystems, Foster City, CA) and the automatic sequencer ABI PRISM 3100 Genetic Analyzer (Applied Biosystems, Foster City, CA).

\section{Results}

At the age of 8 years, short stature, reduced head circumference, cognitive delay and facial dysmorphisms led to investigation of the LIG4 gene involved in Dubowitz syndrome (OMIM \#223370): no mutation was identified. Because of clinical features including chorioretinal coloboma, growth failure, developmental retardation and hearing loss, CHARGE syndrome (OMIM\#214800) was suggested at the age of 9 years. Sequencing of the CHD7, whose mutation explains about $90 \%$ of cases of CHARGE syndrome, excluded this gene as the cause of the patient's phenotype.

The array-CGH performed at the age of 10 years showed the presence of an interstitial microduplication at 18p11.31-p11.23 (6,813,085 × 2, 6,825,044-7,157,962 ×3, $7,193,872 \times 2$ ) of 332,9-380,7 Kb (Fig. 3a). The same duplication, tested through MLPA, was present in the mother of the patient, but not in the father and in the older sister (Fig. 3b). Actually, the apparently healthy mother upon a closer evaluation revealed some mild clinical features of the son, such as partially hearing loss and mild micrognathia. She had a normal head size and her performance at school was within the normal range.

The duplicated region was examined using the human resource websites at NCBI [12] and the archive EnsEMBL [13]. This region contains 3 genes, encoding for a member of the Rho guanosine triphosphatases (ARHGAP28), the laminin subunit $\alpha 1$ (LAMA1) and a 


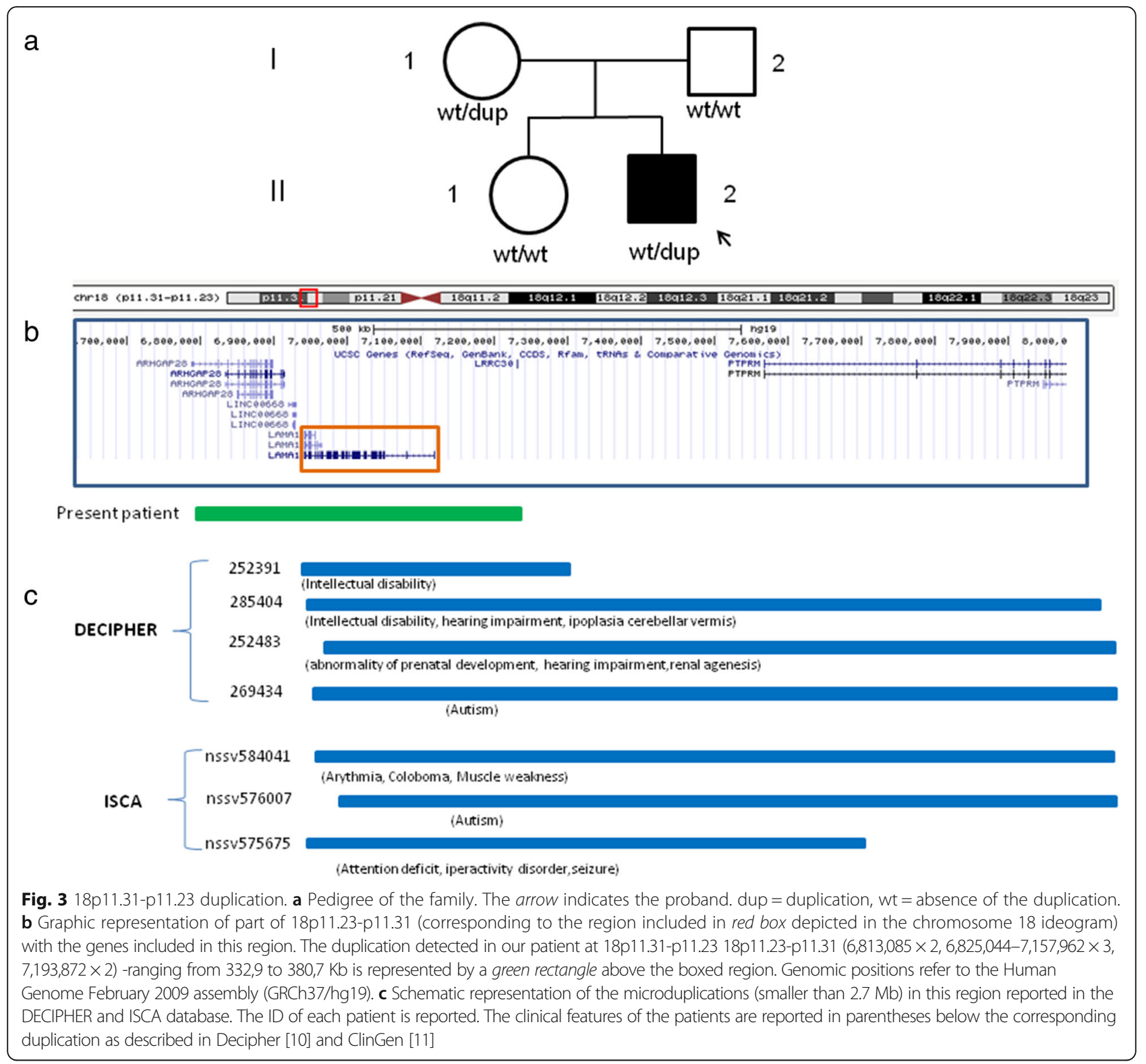

long intergenic non-coding RNA (LINC00668) of unknown function.

\section{Conclusions}

Most microdeletions and microduplications encompass several genes with various functions, creating a challenge in understanding the role of the genes involved in the phenotype. Occasionally, however, these mutations encompass only few genes. Such cases are of special interest in contributing to the understanding of effects of dosage variations of the included genes.

Here we report a $18 \mathrm{p}$ micro-duplication including three genes in a patient with intellectual disability, deafness, GHD and other clinical features. The duplication was inherited from the unaffected mother. In contrast to microdeletions, the interpretation of microduplications often remains unsolved as the functional consequences of these alterations are not well understood. However, analyzing the role of the three genes included in the rearrangement, namely ARHGAP28, LINC00668, LAMA1, might help to elucidate, at least in part, the genotype-phenotype relationship.

The ARHGAP28 encodes for a Rho GTPase activating protein (RhoGAP) that switches RhoA into its inactive form by stimulating the ability of Rho GTPase to hydrolyze GTP to GDP. The Rho GTPases are important in the regulation of reorganization of the actin during the formation of stress fibers. In particular it has been recently reported that in mice Arhgap28 might act as a negative regulator of RhoA, during the formation of 
actin stress fibers in cells of mesenchymal origin [14]. LINC00668 encodes for a long intergenic non coding RNA whose function has not been reported but similarly to the other non coding RNA it might be involved in the regulation of gene expression.

Among the genes included in the duplication, the best known is LAMA1 as it has also been found mutated in humans and animal models. Laminins are a large family of heterotrimeric glycoproteins consisting of a $\alpha, \beta$ and $\gamma$ chain present in the extracellular matrix, essential for the basement membrane assembly and critical for early embryonic development [15]. LAMA1 encodes for the alpha-1 subunit of the Laminin-111 heterotrimer, formed by $\alpha 1, \beta 1$ and $\gamma 1$. Hypomorphic and null LAMA1 mutations in mice and zebrafish cause defects in the retinal inner, limiting membrane development, abnormal retinal blood vessel formation and progressive cell loss from the inner nuclear and ganglion cell layers [16, 17]. In humans, LAMA1 biallelic mutations have been identified in patients affected by cerebellar dysplasia with cysts, presenting defects in the retina development, including retinal dystrophy, absent pigment and atrophy [18]. However, both human and mice phenotypes are determined by inactivating mutations with the consequent absence of a functional product during retinal and cerebellum development, whereas here we detected a duplication of the gene containing region.

We can speculate that an excess of LAMA1 may be involved in the cerebellum and retinal defects observed in our patient by perturbing the interaction with the other subunits in Laminin-111 formation, thus contributing to the cerebellar vermis hypoplasia and retinal coloboma. Alternatively, the long intergenic non-coding RNA (LINC00668) located downstream of the gene, might be involved in $L A M A 1$ transcription regulation and the increased level of this non-coding transcript might alter the local chromatin structure and consequently affect transcription of the nearby genes [19].

Regarding the hearing loss, it is intriguing that laminins have been detected at multiple sites in human and rodent inner ears [20,21]. Furthermore, the $d y$ mouse, a mutant model for congenital muscular dystrophy defective for laminin- $\alpha 2$, also presents hearing loss [22], thus confirming the pleiotropic effect of laminins and reinforcing the evidence of their involvement in deafness.

Although duplications encompassing LAMA1 are not reported in the literature, seven patients with similar partial or complete overlapping imbalances, including this gene, are present in the DECIPHER [10] and ISCA Databases [11] (Fig. 3c). Remarkably, some of these patients present clinical features resembling those observed in our patient, such as hearing impairment in \#285404 and \#252483 and hearing impairment in association with hypoplasia of the cerebellar vermis in \#285404 or
Coloboma in nssv584041 and intellectual disability in \#252391. In all these patients, the minimal critical region contains LAMA1 (Fig. 3c). However, against the involvement of this duplication in the clinical phenotype is the observation that duplications including LAMA1 also represent rare CNVs as reported in the DGV [9].

In any case, the interpretation of the role of this duplication remains challenging, also considering the paucity of similar rearrangements on 18p described in literature. To the best of our knowledge, there are only three interstitial submicroscopic duplications reported involving $18 p$ and none of them overlaps with the one described here [6-8]. In all of these cases, the microduplication was either inherited from a healthy parent $[7,8]$, as in the here presented case, or it was present in unaffected family members [6], in accordance with a dominant model of inheritance with incomplete penetrance. The variability in the phenotype of patients carrying the same unbalances, ranging from severe disorders to healthy phenotype, might be explained with the presence of additional anomalies in the affected patients. This additional hit has been demonstrated in cases in which the aCGH revealed the presence of a second rearrangement that might operate through an additive model or by modifying the phenotype [23]. Further studies are required to establish the pathogenicity of this variation. Similarly to other imbalances with reduced penetrance and variable expressivity, it can be suspected that there might be other co-occurring variations not detectable with conventional aCGH. The complex phenotype of the here described patient could be the consequence of different and independent genetic defects and for example GHD could be determined by a causative mutation in some other gene.

\section{Additional file}

Additional file 1: Supplementary Methods. (DOCX $22 \mathrm{~kb}$ )

\section{Abbreviations \\ aCGH: Array comparative genomic hybridization; GHD: Growth hormone deficiency; BMI: Body mass index; SDS: Standard deviation score; MRI: Magnetic resonance image; IQ: Intelligence quotient; CNVs: Copy number variations}

Acknowledgements

The authors are grateful to Susan West for the English revision of the paper.

\section{Funding}

Not applicable.

Availability of data and materials

Data sharing not applicable to this article as no datasets were generated or analysed during the current study. 


\section{Authors' contributions}

MG and DB performed the genetic analysis and drafted the paper, VM collected the data of the patient, $C M$ and MB contributed in writing the manuscript. All authors read and approved the final manuscript.

\section{Competing interests}

The authors declare that they have no competing interests.

\section{Consent for publication}

Parents' patient have given their informed written consent for publication of the present case report.

\section{Ethics approval and consent to participate}

Parents' patient have given their informed written consent for their son's participation to this study.

\section{Author details}

${ }^{1}$ Laboratory of Genetics, Department of Health Sciences, University of Eastern Piedmont, Novara, Italy. ${ }^{2}$ Internal Medicine and Therapeutics Department, Pediatric and Adolescent Unit, University of Pavia, Fondazione IRCCS Policlinico San Matteo, Pavia, Italy.

Received: 28 September 2016 Accepted: 17 November 2016 Published online: 03 December 2016

\section{References}

1. Hasi-Zogaj M, Sebold C, Heard P, Carter E, Soileau B, Hill A, Rupert D, Perry B, Atkinson S, O'Donnell L, Gelfond J, Lancaster J, Fox PT, Hale DE, Cody JD. A review of 18p deletions. Am J Med Genet C Semin Med Genet. 2015;169:251-64

2. Taine L, Goizet C, Wen ZQ, Chateil JF, Battin J, Saura R, Lacombe D. 18p monosomy with midline defects and a de novo satellite identified by FISH. Ann Genet. 1997:40:158-63.

3. Tonk V, Krishna J. Case report: denovo inherited 18p deletion in a motherfetus pair with extremely variable expression, confirmed by fluorescence in situ hybridization (FISH) analysis. Eur J Obstet Gynecol Reprod Biol. 1997;73:193-6.

4. Artman HG, Morris CA, Stock AD. 18p- syndrome and hypopituitarism. J Med Genet. 1992;29:671-2.

5. Portnoï MF, Gruchy N, Marlin S, Finkel L, Denoyelle F, Dubourg C, Odent S, Siffroi JP, Le Bouc Y, Houang M. Midline defects in deletion 18p syndrome: clinical and molecular characterization of three patients. Clin Dysmorphol. 2007;16:247-52

6. Occella C, Bleidl D, Nozza P, Mascelli S, Raso A, Gimelli G, Gimelli S, Tassano E. Identification of an interstitial 18p11.32-p11.31 duplication including the EMILIN2 gene in a family with porokeratosis of Mibelli. PLoS One. 2013;8:e61311

7. Balasubramanian M, Sithambaram S, Smith K. Inherited duplication of the short arm of chromosome 18p11.32-p11.31 associated with developmental delay/intellectual disability. Clin Dysmorphol. 2016;25:19-22.

8. Kashevarova AA, Nazarenko LP, Skryabin NA, Salyukova OA, Chechetkina NN, Tolmacheva EN, Sazhenova EA, Magini P, Graziano C, Romeo G, Kučinskas V, Lebedev IN. Array CGH analysis of a cohort of Russian patients with intellectual disability. Gene. 2014;536:145-50

9. Database of Genomic Variants: http://dgv.tcag.ca/dgv/app/home. Accessed 1 Sept 2016

10. DECIPHER v9.10: Mapping the clinical genome: https://decipher.sanger.ac.uk Accessed 1 Sept 2016.

11. Clin Gen-Clinical Genome Resource: https://www.clinicalgenome.org. Accessed 1 Sept 2016.

12. NCBI Human Genome Resources: http://www.ncbi.nlm.nih.gov/projects/ genome/guide/human. Accessed 1 Sept 2016

13. EnsEMBL Ensemble Genome Broser 85: http://www.ensembl.org/index.html. Accessed 1 Sept 2016

14. Yeung CY, Taylor SH, Garva R, Holmes DF, Zeef LA, Soininen R, BootHandford RP, Kadler KE. Arhgap28 is a RhoGAP that inactivates RhoA and downregulates stress fibers. PLoS One. 2014;9:e107036.

15. Domogatskaya A, Rodin S, Tryggvason K. Functional diversity of laminins. Annu Rev Cell Dev Biol. 2012;28:523-53.

16. Edwards MM, Mammadova-Bach E, Alpy F, Klein A, Hicks WL, Roux M, Simon-Assmann P, Smith RS, Orend G, Wu J, Peachey NS, Naggert JK,
Lefebvre O, Nishina PM. Mutations in Lama1 disrupt retinal vascular development and inner limiting membrane formation. J Biol Chem. 2010;285:7697-711.

17. Edwards MM, McLeod DS, Grebe R, Heng C, Lefebvre O, Lutty GA. Lama1 mutations lead to vitreoretinal blood vessel formation, persistence of fetal vasculature, and epiretinal membrane formation in mice. BMC Dev Biol. 2011;11:60.

18. Aldinger KA, Mosca SJ, Tétreault M, Dempsey JC, Ishak GE, Hartley T, Phelps IG, Lamont RE, O'Day DR, Basel D, Gripp KW, Baker L, Stephan MJ, Bernier $F P$, Boycott KM, Majewski J. Mutations in LAMA1 cause cerebellar dysplasia and cysts with and without retinal dystrophy. Am J Hum Genet. 2014;95:227-34

19. Li X, Wu Z, Fu X, Han W. IncRNAs: insights into their function and mechanics in underlying disorders. Mutat Res Rev Mutat Res. 2014;762:1-21.

20. Yamashita $H$, Bagger-Sjoback D, Wersall J. The presence of laminin in the fetal human inner ear. Eur Arch Otorhinolaryngol. 1991;248:479-82.

21. Rodgers L, Barritt JH, Miner D, Cosgrove D. The laminins in the murine inner ear: developmental transitions and expressions in cochlear basement membranes. Hear Res. 2001;158:39-50.

22. Pillers DA, Kempton JB, Duncan NM, Pang J, Dwinnell SJ, Trune DR. Hearing loss in the laminin-deficient dy mouse model of congenital muscular dystrophy. Mol Genet Metab. 2002;76:217-24.

23. Girirajan S, Rosenfeld JA, Cooper GM, Antonacci F, Siswara P, Itsara A, Vives L, Walsh T, McCarthy SE, Baker C, Mefford HC, Kidd JM, Browning SR, Browning BL, Dickel DE, Levy DL, Ballif BC, Platky K, Farber DM, Gowans GC, Wetherbee JJ, Asamoah A, Weaver DD, Mark PR, Dickerson J, Garg BP, Ellingwood SA, Smith R, Banks VC, Smith W, McDonald MT, Hoo JJ, French BN, Hudson C, Johnson JP, Ozmore JR, Moeschler JB, Surti U, Escobar LF, ElKhechen D, Gorski JL, Kussmann J, Salbert B, Lacassie Y, Biser A, McDonaldMcGinn DM, Zackai EH, Deardorff MA, Shaikh TH, Haan E, Friend KL, Fichera M, Romano C, Gécz J, DeLisi LE, Sebat J, King MC, Shaffer LG, Eichler EE. A recurrent 16p12.1 microdeletion supports a two-hit model for severe developmental delay. Nat Genet. 2010:42:203-9.

\section{Submit your next manuscript to BioMed Central} and we will help you at every step:

- We accept pre-submission inquiries

- Our selector tool helps you to find the most relevant journal

- We provide round the clock customer support

- Convenient online submission

- Thorough peer review

- Inclusion in PubMed and all major indexing services

- Maximum visibility for your research

Submit your manuscript at www biomedcentral.com/submit
) Biomed Central 